\title{
Stem Cell Therapy for Erectile Dysfunction: A Critical Review
}

\author{
Ching-Shwun Lin,, Zhong-Cheng Xin, ${ }^{2}$ Zhong Wang, ${ }^{3}$ Chunhua Deng, ${ }^{4}$ \\ Yun-Ching Huang, ${ }^{5}$ Guiting Lin, ${ }^{1}$ and Tom F. Lue ${ }^{1}$
}

Erectile dysfunction (ED) is a prevailing health problem that seriously impacts quality of life. Current treatment options are less effective for patients having cavernous nerve $(\mathrm{CN})$ injury or diabetes mellitus-related ED. These 2 types of ED are thus the main focus of past and current stem cell (SC) therapy studies. In a total of 16 studies so far, rats were exclusively used as disease models and SCs were mostly derived from bone marrow, adipose tissue, or skeletal muscle. For tracking, SCs were labeled with LacZ, green fluorescent protein, 4',6-diamidino-2phenylindole, DiI, bromodeoxyuridine, or 5-ethynyl-2-deoxyuridine, some of which might have led to data misinterpretation. SC transplantation was done exclusively by intracavernous (IC) injection, which has been recently shown to have systemic effects. Functional assessment was done exclusively by measuring increases of IC pressure during electrostimulation of CN. Histological assessment usually focused on endothelial, smooth muscle, and $\mathrm{CN}$ contents in the penis. In general, favorable outcomes have been obtained in all trials so far, although whether SCs had differentiated into specific cell lineages remains controversial. Recent studies have shown that intracavernously injected SCs rapidly escaped the penis and homed into bone marrow. This could perhaps explain why intracavernously injected SCs had systemic antidiabetic effects and prolonged anti-ED effects. These hypotheses and the differentiation-versus-paracrine debate require further investigation.

\section{Introduction}

$\mathrm{E}$ RECTILE DYSFUNCTION (ED) is a prevailing health problem $\triangle$ that seriously impacts the quality of life of men and their spouses or partners [1]. In the United States alone, an estimated 30 million men suffer from different degrees of ED [2]. The majority of ED patients can now be treated satisfactorily with phosphodiesterase type-5 (PDE5) inhibitors, such as sildenafil (Viagra; Pfizer Inc., New York, NY), vardenafil (Levitra; Bayer AG, Leverkusen, Germany), and tadalafil (Cialis; Lily-ICOS, Indianapolis, IN) [3]. However, PDE5 inhibitors are strictly contraindicated with concomitant nitrates because of the danger of their synergistic hypotensive effects [3]. PDE5 inhibitors are known to cause a variety of adverse side effects that may reduce their suitability for some patients [3]. More importantly, PDE5 inhibitors are only partially effective in treating certain types of ED including those associated with diabetes mellitus (DM) and surgery-induced $\mathrm{CN}$ injuries (mainly due to radical prostatectomy) [3]. As such, alternative treatments, particularly those that can treat the underlying disease process of ED, are highly desirable. In this regard, one of the strategies currently being evaluated is stem cell (SC) therapy.

\section{Rationale for Using SC Therapy}

Despite being conventionally classified in the urinary system, the penis is in fact a vascular organ. The penile corpora cavernosa are composed of sinusoids that are lined with a single layer of endothelial cells (ECs) and are surrounded by multiple layers of circular and longitudinal cavernous smooth muscle cells (CSMCs) (Fig. 1). In the flaccid penis, CSMCs are in a contracted state and maintain a small amount of blood flow in and out of the sinusoids. When a man is sexually aroused, nitric oxide (NO) is released from terminal fibers of cavernous nerves (CNs) and enters the neighboring CSMCs, resulting in CSMC relaxation. Blood rushes in as a consequence and engorges the sinusoids, leading to the initial phase of penile erection. Maintenance of erection, that is, continued CSMC relaxation, is believed to derive from additional NO release from the sinusoidal ECs. The further sinusoidal engorgement causes

\footnotetext{
${ }^{1}$ Knuppe Molecular Urology Laboratory, Department of Urology, School of Medicine, University of California, San Francisco, California.

${ }^{2}$ Andrology Center, Peking University First Hospital, Beijing, China.

${ }^{3}$ Department of Urology, Ninth People's Hospital Affiliated to Medical College of Shanghai Jiao-Tong University, Shanghai, China.

${ }^{4}$ Department of Urology, First Affiliated Hospital of Sun Yet-Sen University, Guangzhou, China.

${ }^{5}$ Division of Urology, Department of Surgery, Chang Gung Memorial Hospital, Chia-Yi, Taiwan, China.
} 
FIG. 1. Penile histology of a normal rat. The cross-section of rat penis was stained with Alexa-488-conjugated phalloidin, which detects smooth muscle (green stain), with Alexa-594-conjugated antiRECA antibody, which detects endothelium (red stain), and with DAPI, which detects cell nuclei (blue stain). DAPI, 4',6-diamidino-2-phenylindole; CC, corpus cavernosum; Pha, phalloidin; RECA, rat endothelial cell antigen.
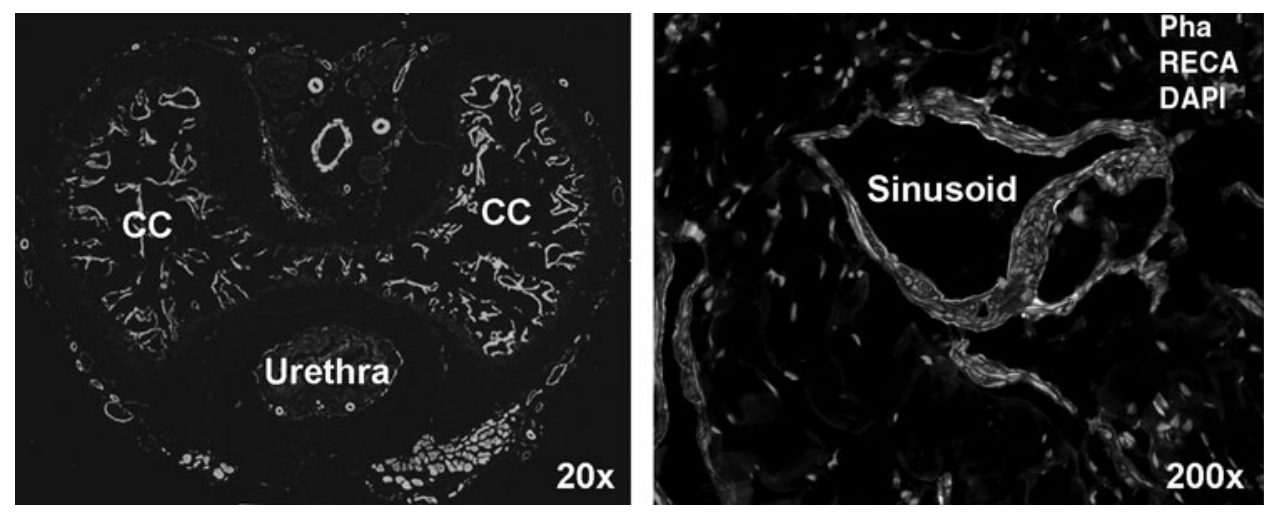

the compression of venules located between the trabeculae and the tunica albuginea, resulting in nearly total occlusion of venous outflow. This combination of sinusoidal engorgement and venous occlusion leads to the full erection of the penis [4]. Thus, structurally, the key components of erection are the ECs, CSMCs, and CN [more specifically, neuronal nitric oxide synthase (nNOS)-positive nerves], and functionally, accurate interactions among these 3 constituents are critical. In different types of ED, these structures and/or interactions are often altered, as described briefly in the following text.

The purpose of a radical prostatectomy is to remove the cancerous prostate; however, the procedure can damage the $\mathrm{CN}$, which run alongside the prostate [5]. The short-term consequence of $\mathrm{CN}$ injury is neurogenic $\mathrm{ED}$, which is reversible, whereas the long-term consequence is atrophy of CSMCs, which can lead to irreversible ED [6]. In men with $\mathrm{DM}$, the high blood glucose also causes reduction of $\mathrm{CN}, \mathrm{EC}$, and CSMC contents [7]. In men with hyperlipidemia, impaired EC function is well documented, but whether it is accompanied with structural changes is not as certain [7]. In our recent studies we have quantified structural changes in the penises of rats with $\mathrm{CN}$ injury, type $2 \mathrm{DM}$ (T2DM), and hyperlipidemia [8-10]; these changes are summarized in Fig. 2. Note that hyperlipidemia was induced by high-fat feeding, and T2DM by high-fat feeding plus streptozotocin injection. High-fat feeding causes increased CSM content in the rat [10], and this may have compensated the CSM loss that is usually associated with DM, resulting in the preservation of CSM in the T2DM rats [8].

SCs are believed to be able to differentiate into various cell types including ECs, smooth muscle cells (SMCs), Schwann cells, and neurons [11]. Therefore, SC therapy for ED was originally based on the hypothesis that transplantation of SCs into penis through intracavernous (IC) injection might replenish the depleted EC and/or CSMC pools. However, in published studies whether cellular differentiation occurred in the treated animals is controversial and will be discussed in more details in a later section under Histological assessment. On the other hand, there were also considerations that IC transplanted SCs might encourage the regeneration of the host's own ECs and CSMCs or might restore proper interactions between ECs and SMCs. In other words, paracrine actions as opposed to cellular differentiation are responsible for SCs' therapeutic efficacy, and based on several of our studies in both ED and non-ED fields, this seems to be the main mechanism [12].
With regard to restoring damaged $\mathrm{CN}$, it should be pointed out that the nerve cell bodies are located in the major pelvic ganglia (MPG) some distance away from the penis. As such, in the first SC-for-ED study, SCs were injected into the MPG of one group of $\mathrm{CN}$ injury rats, and the results showed improved erectile function [13]. Importantly, in the same study, SCs were also injected into the penis of another group of CN injury rats, and similar results were obtained. This finding is cited as basis for using IC injection in the next SCs for CN injury study [14], and since then this injection method has been apparently accepted as legitimate, although no one knew how it worked until now (see Stem cell transplantation section).

\section{Current Status}

There are currently 16 publications in the field of SC therapy for ED (Table 1). Five additional publications tested SC transplantation without assessing erectile function and are thus not SC therapy per se.

\section{Clinical Trial}

A clinical trial of SC therapy for ED has been carried out in Korea [25]. In this study, 7 T2DM men ranging from 57 to 87 years of age were each treated with IC injection of 15 million allogeneic umbilical cord blood SCs. Morning erection was regained in 3 patients within 1 month and in 6 patients within 3 months. However, despite having increased penile rigidity, none was able to achieve vaginal penetration unless aided by taking sildenafil before coitus. During 11-month follow-up, only one treated subject maintained erection sufficient for coitus. Interestingly, SC therapy appears to have antidiabetes effects as all treated subjects except the oldest had reduced blood glucose and glycosylated hemoglobin levels. These results provide further evidence not only for the frequently observed antidiabetes effects of SCs but also for IC injection being a systemic application as we recently reported (see Stem cell transplantation section). Also noteworthy is that, despite being allogeneic in the absence of immunosuppressant, SC transplantation did not cause any adverse effects, thus providing further evidence for the immunosuppressive effects of SCs.

\section{Preclinical Trials}

A typical preclinical trial of SC therapy for ED is schematically depicted in Fig. 3. It involves the isolation, 

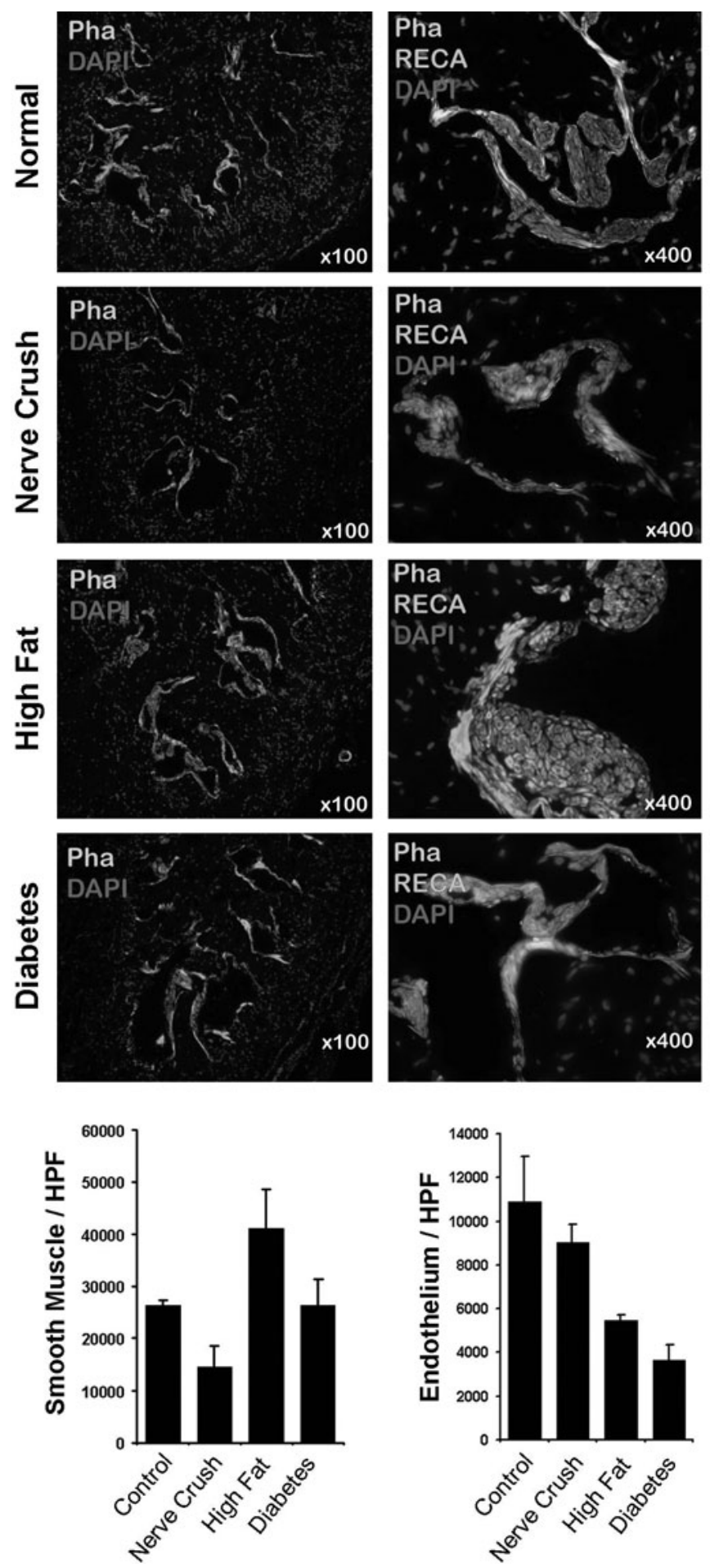

cultivation, sorting, and modification of SCs, followed by labeling them with a cell-tracking agent. The labeled SCs were then injected into the corpus cavernosum (IC injection) of an ED animal model. Weeks or months later, the animals are tested for erectile function, usually by measurement of increases in intracavernous pressure (ICP) during electrostimulation of $\mathrm{CN}$. The animals are then sacrificed for histological assessment of corpus cavernosum and tracking of injected SCs.
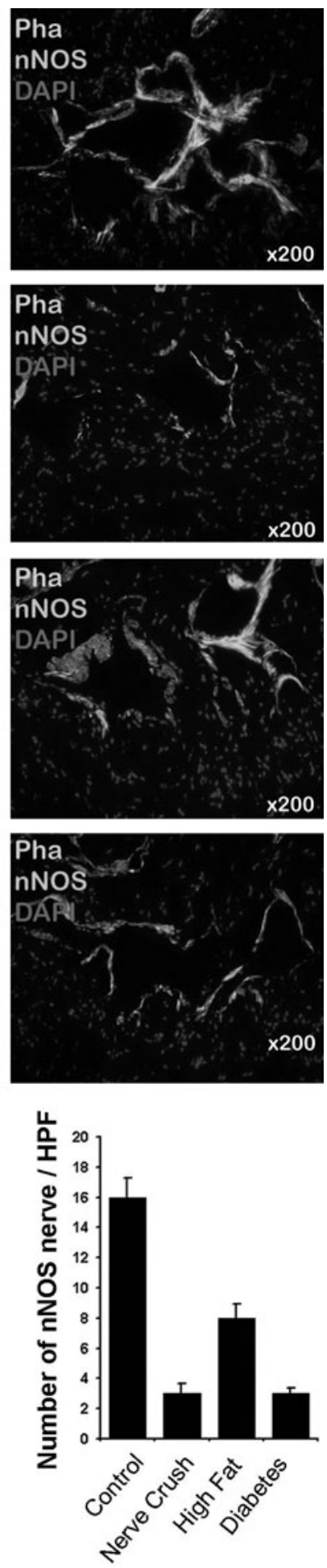

FIG. 2. Histological changes in the penises of ED rats. Representative images from normal rats and indicated ED models illustrate ED-associated changes in smooth muscle (left column), endothelium (middle column), and nNOS-positive nerves (right column). Quantification of these changes in 9 rats in each group of rats was done as described in our previous studies, and the results are shown at the bottom. For smooth muscle and endothelium, the unit on the $Y$-axis is number of pixels/high-power field (HPF). For nNOS, the unit is number/HPF, where "number" refers to the red dots seen in the images. Note that all tissue sections were costained with DAPI for the visualization of cell nuclei (blue). ED, erectile dysfunction; nNOS, neuronal nitric oxide synthase.

\section{Animal models}

Rat is the most commonly used animal in ED research and was used in all preclinical SC-for-ED studies thus far. Underscoring clinical needs, $\mathrm{CN}$ injury and DM are the most commonly tested disease models. $\mathrm{CN}$ injury, tested in 7 studies, was induced by either crush or resection of $\mathrm{CN}$ bilaterally. T2DM patients outnumber T1DM patients 9 to 1 , yet most experimental studies chose T1DM over T2DM. This 


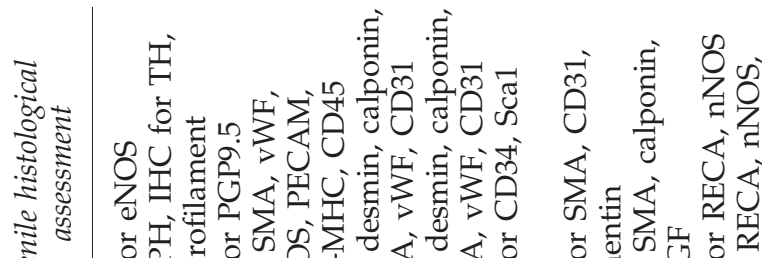

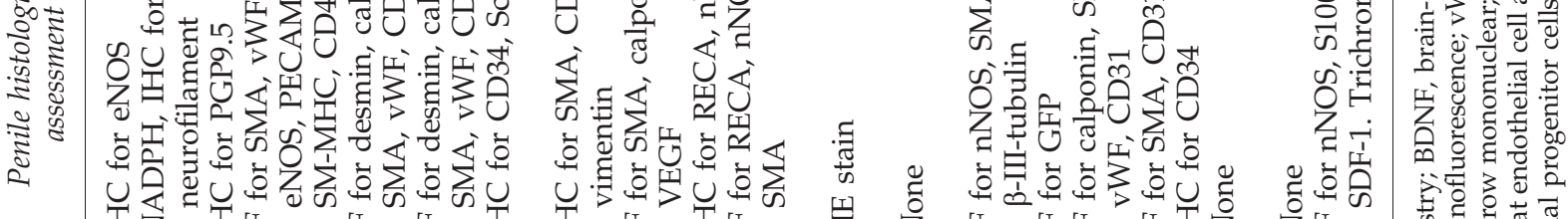

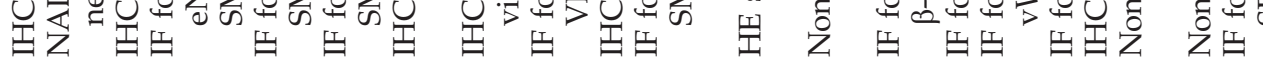

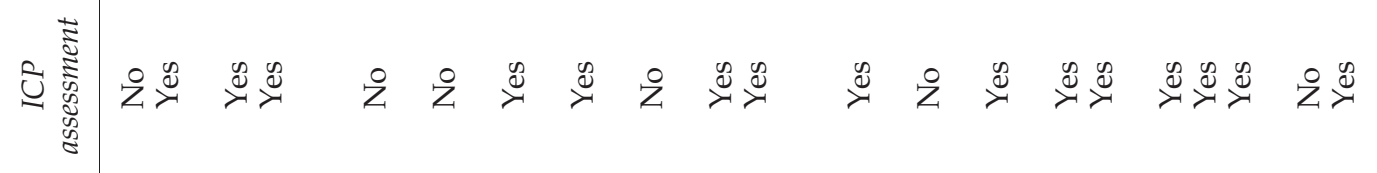

을 홍

믈 द्व

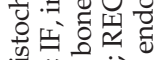

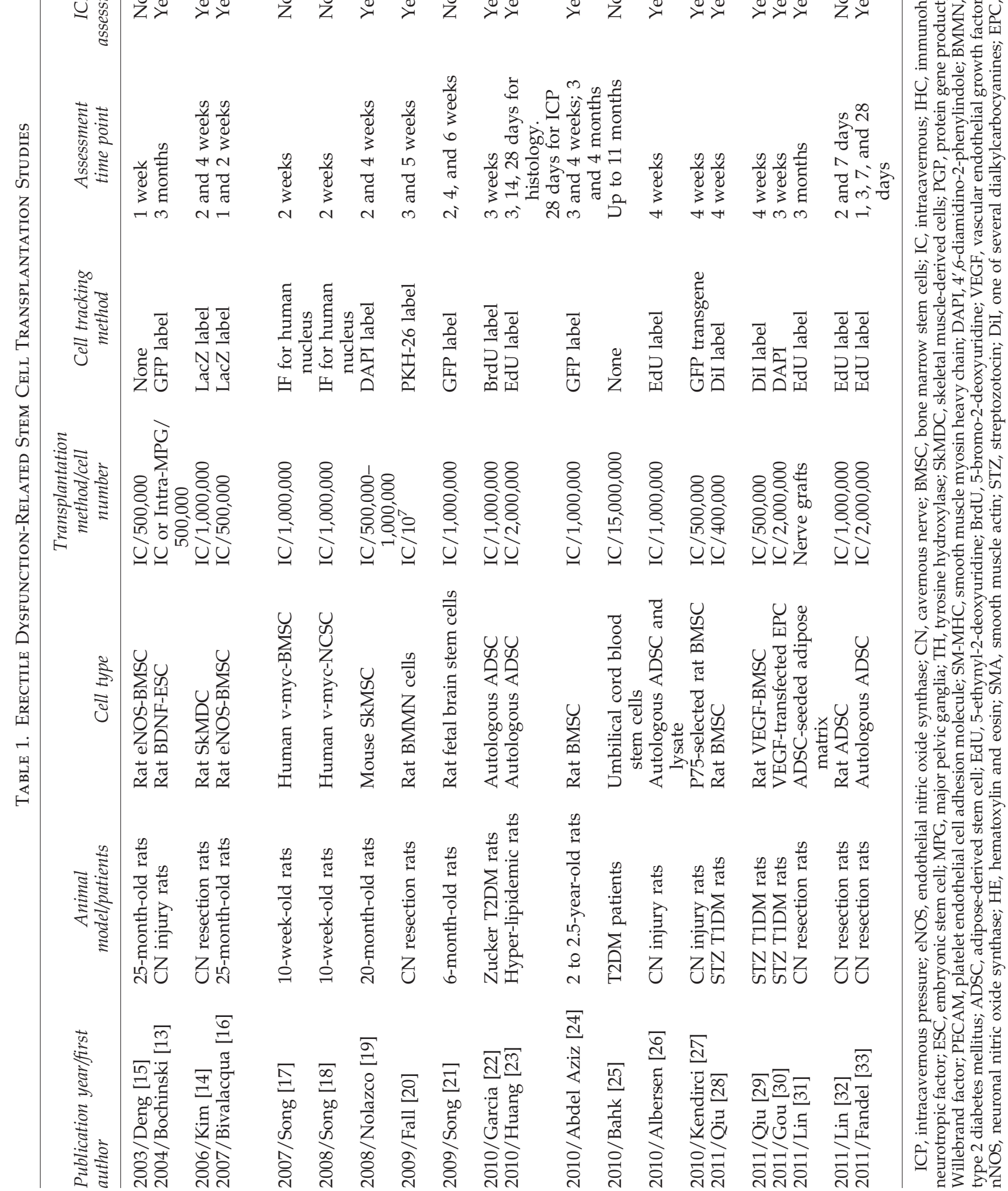




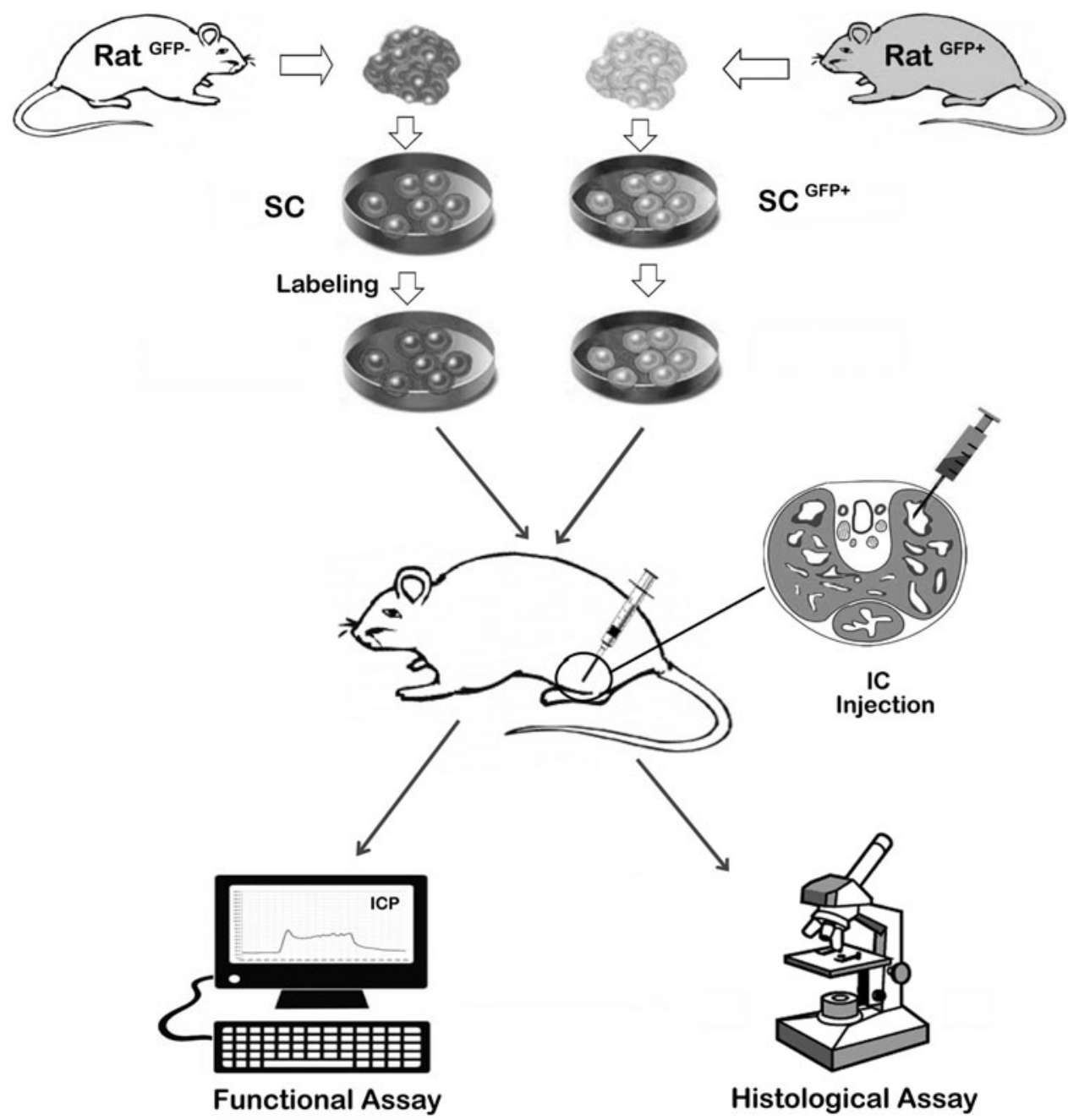

FIG. 3. A schematic representation of the experimental procedures of a typical preclinical stem cell therapy for ED. The donor rat and recipient rat can be the same (autologous) or different (allogeneic). The isolation and cultivation of SCs vary from one type to another. Modification and sorting of SCs are desired by some researchers, although a higher benefit versus risk ratio has not been demonstrated. Labeling of SCs, which is unnecessary if from a GFP donor rat, usually incorporates a chemical agent that can be later detected by color or fluorescence. Transplantation of the labeled SCs has so far been conducted universally by IC injection, as indicated with the crosssectional view of the penis of an animal whose erectile function has been compromised by various means, for example, $\mathrm{CN}$ injury and streptozotocin injection. Weeks or months after SC transplantation, the animals are tested for erectile function, usually by measurement of increases in intracavernous pressure (ICP) during electrostimulation of

CN. The animals are then sacrificed for histological assessment of corpus cavernosum and identification of the injected SCs. SCs, stem cells; GFP, green fluorescence protein; IC, intracavernous; CN, cavernous nerve.

is due to the fact that T1DM can be easily induced by intraperitoneal injection of streptozotocin, whereas T2DM is more difficult to induce or requires the purchase of costly genetically modified animals. So, in SC-for ED field, T1DM model was used in 3 studies and T2DM in 1. Aging-related ED is largely manageable with PDE5 inhibitors, so SC studies in this category (a total of 3 ) were most likely motivated by not requiring any special treatment on the animal. Finally, hyperlipidemia-associated ED, which requires feeding animals with costly high-fat diet, was used in one study.

\section{Stem cells}

Types of SCs that have been used in experimental ED treatment (number of studies in brackets) are bone marrow (6), adipose (5), skeletal muscle (2), embryonic (1), endothelial progenitor (1), and umbilical cord blood (1, a clinical trial). Some studies have provided reason for choosing 1 particular SC type over the other; however, personal preferences and/or preexisting circumstances (eg, prior experience with a particular type of SC) probably played bigger roles than sound scientific rationales did. In any case, the pros and cons of various types of SCs can be found abundantly elsewhere and will not be discussed here.

Nearly all transplantations were done either autologously or allogeneically, the single exception being from mouse to rat. The transplanted cell number averages around 1 million per recipient rat. Most studies (total of 10) employed unmodified SCs, whereas others used SCs that were transfected or fractionated or in combination with other agents. Transfection or fractionation inevitably introduces risk factors (eg, virus) into the system and/or substantially reduces the number of treatment cells. Thus, knowing that the majority of studies employed unmodified SCs with satisfactory outcomes, the need to use modified or sorted SCs requires additional evidence.

\section{Cell labeling}

A wide variety of methods have been used to monitor the distribution and survival of transplanted SCs. In SC-ED field, 2 studies by the same group of researchers transplanted human SCs to rats; therefore, cell tracking was done by the identification of human-specific nuclear protein. However, 
these studies did not assess erectile function and thus will not be discussed further. All other SC-ED studies used cells labeled with LacZ, 4',6-diamidino-2-phenylindole (DAPI), green fluorescent protein (GFP), DiI (also known as PKH-26), bromodeoxyuridine (BrdU), or 5-ethynyl-2-deoxyuridine (EdU). Because the accuracy of data interpretation depends on the reliability of these labeling methods, potential problems are summarized below.

Lac $Z$ is a bacterial gene that encodes $\beta$-galactosidase ( $\beta$ gal); however, many mammalian cells and tissues contain endogenous $\beta$-gal, making the detection of LacZ-transfected cells after their transplantation technically challenging [34]. GFP is a protein from jellyfish. However, because of autofluorescence in mammalian tissues, GFP detection can seem like "seeing the wood through the trees" [35]. DAPI binds to DNA noncovalently; therefore, it can leak from labeled cells after transplantation and be adsorbed by host cells, resulting in false-positive detection [36]. DiI binds to cell membrane noncovalently and can leak from transplanted cells to host cells. In addition, because of DiI's cytotoxicity, transplanted cell preparations may contain debris of dead cells. Adsorption of this Dil-labeled debris by host cells can lead to falsepositive identification [37-41]. BrdU is incorporated into newly synthesized DNA and such labeled cells are detected with anti-BrdU antibody. However, the immnodetection of BrdU requires harsh treatment of tissue samples, resulting in distorted histological images [42]. In addition, the denaturing treatment can cause loss of antigenicity of cellular proteins, making it impossible to detect cellular differentiation through immunohistochemical colocalization of cell typespecific protein. Even if the protein of interest survives the denaturing treatment, it is still difficult to identify the BrdU label with confidence, because its brown color cannot be easily distinguished from the purplish nuclear stain [43]. EdU is a newer thymidine analog and is detected by a simple chemical reaction that requires no special tissue treatment [42]. However, similar to BrdU, if a labeled cell is replicative after transplantation, its EdU label gets diluted with each round of cell division. So, long-term detection of transplanted cells is possible only if the cells are relatively quiescent. In our experience with EdU-labeled adipose-derived SCs (ADSCs), their detection in transplanted tissue is possible for at least 5 months after transplantation.

\section{Stem cell transplantation}

Before the introduction of PDE5 inhibitors, which are taken orally, IC injection of erectogenic agents was the most effective treatment for ED [4]. Indeed, even nowadays patients who do not respond to or cannot take PDE5 inhibitors are still prescribed with IC injection of vasodilators. As this route of drug administration targets the organ of failure directly, it is commonly believed that IC injection is a locally applied intervention. However, we have observed that IC injected growth factors were able to restore erectile function through repair of damaged $\mathrm{CN}$, whose cell bodies reside in the MPG [44-46]. Further, in our first SC-for-ED study, we observed that intracavernously injected SCs could treat CN injury-related ED [13], and all subsequent studies using different types of SCs confirmed the validity of this injection method for treating CN injury-related ED. Together, these data strongly suggest that IC injection is systemic in nature.
In all of our published SC-for-ED studies we reported difficulties in finding the transplanted SCs in penile tissues even though the animals clearly demonstrated functional and structural improvements $[13,22,23,26]$. In studies published by others, intracavernously injected SCs were similarly difficult to find. In one of our studies we examined the presence of SCs in the penis at 2, 14, and 28 days after IC injection; the results clearly showed a time-dependent decline of the number of SCs [23]. In our recent studies we conducted more definitive quantitative analyses and the results showed that the majority of intracavernously injected SCs exited the penis within 1 day $[32,33]$. Further, in 1 of these 2 studies we showed that intracavernously injected SCs preferentially traveled to the bone marrow [32]; in the other we found that intracavernously injected SCs also traveled to the MPG of CN injury rats, and this appears to be mediated by upregulated SDF-1 in the MPG [33]. Together, these data suggest that (i) IC injection is essentially like intravenous (IV) injection-because of the fact that the cavernous sinusoids are essentially bundled venules (Fig. 1), (ii) the therapeutic efficacy of SCs for CN injury is due to SC trafficking to the MPG, (iii) systemically (IC or IV) applied SCs home-in to bone marrow, in support of the concept that mesenchymal SCs originate from bone marrow, and (iv) home-in of SCs to bone marrow may permit establishment of SC reservoirs for sustained regenerative and/or repair activities.

\section{Functional assessment}

In animal experimentation, the most commonly used method for functional assessment of erection is measurement of intracavernous pressure (ICP) during electrostimulation of $\mathrm{CN}$. This procedure requires laparotomy followed by sacrificing the animals; therefore, it is done near the end (most commonly at 1 month post-treatment) of a preclinical trial. As mentioned in the Rationale for Using SC Therapy section earlier, sexual stimulation triggers $\mathrm{CN}$ to release $\mathrm{NO}$, which then causes CSMC relaxation and sinusoidal engorgement. In animal experiments, stimulation of $\mathrm{CN}$ with electric current mimics sexual stimulation and causes an increase of ICP that can approach systemic blood pressure, depending on the amperage of the applied electric current. Typically, at settings of $1.5 \mathrm{~mA}, 20 \mathrm{~Hz}$, and pulse width $0.2 \mathrm{~ms}$, the electrostimulation causes an increase of ICP (in $\mathrm{cmH}_{2} \mathrm{O}$ ) from a baseline of 20 to around 100 in normal rats. In ED rats, the rise is usually to around 30, and a successful SC treatment usually restores the value to about 70 .

\section{Histological assessment}

At the end of functional assessment, penile tissues are commonly prepared for examination by immunohistochemistry or immunofluorescence. The purposes of these examinations are to (i) locate transplanted SCs, (ii) correlate structural with functional changes, and (iii) identify possible SC differentiation. Localization of transplanted cells was discussed earlier under Cell labeling section. Assessment of structural changes invariably focuses on the 3 key components that regulate penile erection, ECs, CSMCs, and CN. ECs are commonly identified with antibodies against rat endothelial cell antigen, CD31, endothelial nitric oxide synthase, and/or von Willebrand factor (vWF). CSMCs are most 
commonly detected with anti-smooth muscle actin (antiSMA) antibody. The most functionally relevant marker for $\mathrm{CN}$ is nNOS, as it identifies NO-releasing nerve fibers.

The concept of SC therapy was originally based on the premise that SCs have the ability to differentiate into various cell lineages. Thus, most SC therapy studies have strived to identify such events by checking whether the labeled SCs express cell type-specific proteins such as CD31 for ECs and SMA for CSMCs. So, it is obvious that the accurate identification of cell differentiation depends on the reliability of the SC trait/label, the differentiated cell marker, and the histological image. As discussed earlier in the Cell labeling section, with the exception of EdU, cell labels that have been employed in SC-ED studies cannot be detected with confidence. Moreover, histological images presented in most SC-ED studies are of low resolution and thus difficult to judge whether the so-called protein expression is indeed cellularly localized. In our experience, seemingly colocalized stains at low magnification often turned out not to be cellularly associated when viewed at higher magnifications (eg, 1,000×). Thus, it is crucial that claims of cell differentiation be backed by clearly discernable histological images.

\section{Future Directions}

As CN injury- and DM-related ED patients are less responsive to PDE5 inhibitors, these 2 types of ED will continue to be the main targets for future research. Current $\mathrm{CN}$ injury rat models have been well characterized and are clinically relevant; they can thus continue to be used for future SCs for ED research. On the other hand, current DM models either are too costly or do not adequately represent clinical situations. To mitigate these problems, we recently established an inexpensive T2DM rat model that exhibits ED symptoms and penile structural changes that resemble those of T2DM patients [8]. This model can thus generate more clinically relevant data in future SC-ED studies.

With regard to choosing a particular SC type, it is important to consider what is most practically applicable in clinical situations. At present, ADSCs is the only cell type that can be isolated and autologously transplanted on a same-day basis. Further, several devices for automated isolation of ADSCs are now commercially available. Thus, in terms of cost, risks, ethics, expediency, and effectiveness, ADSCs should compete very favorably. The most significant risk-promotion of tumor growth-is shared by different types of SCs and requires further research.

As we have now demonstrated that IC injection is similar to IV injection [32], it is advisable that future SC-ED studies examine the systemic distribution of the transplanted SCs. This of course requires that the cells be labeled with a reliable tracking dye. In our experience with many commonly employed dyes such as BrdU, DiI, DAPI, GFP, and EdU, we have found that labeling with EdU is the easiest and most reliable. With regard to SC distribution, we advise the examination of bone marrow as SCs seem to have a tendency to travel there. What do these SCs do in bone marrow is the next question that needs to be addressed. Specifically, do they play any role in terms of short-term and long-term therapeutic efficacy? Finally, the issue of cellular differentiation versus paracrine action needs to be further investi- gated. To do so, first, it is important to know that, although cellular differentiation is a presumed SC property, it does not have to happen in order for SC to exert therapeutic effects. With this concept in mind, then, a reliable tracking dye is used to label the SCs, followed by generating high-quality high-resolution histological images, and it should be possible to make accurate and unbiased interpretations.

\section{Acknowledgments}

This work was supported by grants from the Arthur Rock Foundation and the National Institutes of Health (DK045370).

\section{Author Disclosure Statement}

No competing financial interests exist.

\section{References}

1. Litwin MS, RJ Nied and N Dhanani. (1998). Health-related quality of life in men with erectile dysfunction. J Gen Intern Med 13:159-166.

2. Nehra A. (2007). Oral and non-oral combination therapy for erectile dysfunction. Rev Urol 9:99-105.

3. Dorsey P, C Keel, M Klavens and WJ Hellstrom. (2010). Phosphodiesterase type 5 (PDE5) inhibitors for the treatment of erectile dysfunction. Expert Opin Pharmacother 11:1109-1122.

4. Lue TF. (2000). Erectile dysfunction. N Engl J Med 342: 1802-1813.

5. Mulhall JP, AJ Bella, A Briganti, A McCullough and G Brock. (2010). Erectile function rehabilitation in the radical prostatectomy patient. J Sex Med 7:1687-1698.

6. Iacono F, R Giannella, P Somma, G Manno, F Fusco and V Mirone. (2005). Histological alterations in cavernous tissue after radical prostatectomy. J Urol 173:1673-1676.

7. Gratzke C, J Angulo, K Chitaley, YT Dai, NN Kim, JS Paick, U Simonsen, S Uckert, E Wespes, et al. (2010). Anatomy, physiology, and pathophysiology of erectile dysfunction. J Sex Med 7:445-475.

8. Albersen M, G Lin, TM Fandel, H Zhang, X Qiu, CS Lin and TF Lue. (2011). Functional, metabolic, and morphologic characteristics of a novel rat model of type 2 diabetesassociated erectile dysfunction. Urology 78:e1-e8.

9. Lin G, X Qiu, TM Fandel, M Albersen, Z Wang, TF Lue and CS Lin. (2011). Improved penile histology by phalloidin stain: circular and longitudinal cavernous smooth muscles, dual-endothelium arteries, and erectile dysfunction-associated changes. Urology [Epub ahead of print]; DOI: 10.1016/j.urology.2011.06.021.

10. Qiu X, TM Fandel, G Lin, YC Huang, YT Dai, TF Lue and CS Lin. (2011). Cavernous smooth muscle hyperplasia in a rat model of hyperlipidemia-associated erectile dysfunction. BJU Int [Epub ahead of print]; DOI: 10.1111/j.1464-410X. 2011.10162.x.

11. Lin CS, ZC Xin, CH Deng, H Ning, G Lin and TF Lue. (2008). Recent advances in andrology-related stem cell research. Asian J Androl 10:171-175.

12. Lin CS. (2010). Advances in stem cell therapy for the lower urinary tract. World J Stem Cells 2:1-4.

13. Bochinski D, GT Lin, L Nunes, R Carrion, N Rahman, CS Lin and TF Lue. (2004). The effect of neural embryonic stem cell therapy in a rat model of cavernosal nerve injury. BJU Int 94:904-909. 
14. Kim Y, F de Miguel, I Usiene, D Kwon, N Yoshimura, J Huard and MB Chancellor. (2006). Injection of skeletal muscle-derived cells into the penis improves erectile function. Int J Impot Res 18:329-334.

15. Deng W, TJ Bivalacqua, NN Chattergoon, AL Hyman, JR Jeter, Jr. and PJ Kadowitz. (2003). Adenoviral gene transfer of eNOS: high-level expression in ex vivo expanded marrow stromal cells. Am J Physiol Cell Physiol 285:C1322-C1329.

16. Bivalacqua TJ, W Deng, M Kendirci, MF Usta, C Robinson, BK Taylor, SN Murthy, HC Champion, WJ Hellstrom and PJ Kadowitz. (2007). Mesenchymal stem cells alone or ex vivo gene modified with endothelial nitric oxide synthase reverse age-associated erectile dysfunction. Am J Physiol Heart Circ Physiol 292:H1278-H1290.

17. Song YS, HJ Lee, IH Park, WK Kim, JH Ku and SU Kim. (2007). Potential differentiation of human mesenchymal stem cell transplanted in rat corpus cavernosum toward endothelial or smooth muscle cells. Int J Impot Res 19:378385.

18. Song YS, HJ Lee, IH Park, IS Lim, JH Ku and SU Kim. (2008). Human neural crest stem cells transplanted in rat penile corpus cavernosum to repair erectile dysfunction. BJU Int 102:220-224; discussion 224.

19. Nolazco G, I Kovanecz, D Vernet, RA Gelfand, J Tsao, MG Ferrini, T Magee, J Rajfer and NF Gonzalez-Cadavid. (2008). Effect of muscle-derived stem cells on the restoration of corpora cavernosa smooth muscle and erectile function in the aged rat. BJU Int 101:1156-1164.

20. Fall PA, M Izikki, L Tu, S Swieb, F Giuliano, J Bernabe, R Souktani, C Abbou, S Adnot, S Eddahibi and R Yiou. (2009). Apoptosis and effects of intracavernous bone marrow cell injection in a rat model of postprostatectomy erectile dysfunction. Eur Urol 56:716-725.

21. Song Y, N Mehta, B Sheh, F Saljooque, HS U and M Rajasekaran. (2009). Transdifferentiation of rat fetal brain stem cells into penile smooth muscle cells. BJU Int 104:257-262.

22. Garcia MM, TM Fandel, G Lin, AW Shindel, L Banie, CS Lin and TF Lue. (2010). Treatment of erectile dysfunction in the obese type 2 diabetic ZDF rat with adipose tissue-derived stem cells. J Sex Med 7:89-98.

23. Huang YC, H Ning, AW Shindel, TM Fandel, G Lin, AM Harraz, TF Lue and CS Lin. (2010). The effect of intracavernous injection of adipose tissue-derived stem cells on hyperlipidemia-associated erectile dysfunction in a rat model. J Sex Med 7:1391-1400.

24. Abdel Aziz MT, S El-Haggar, T Mostafa, H Atta, H Fouad, S Mahfouz, L Rashed, D Sabry, A Senbel and GA Ali. (2010). Effect of mesenchymal stem cell penile transplantation on erectile signaling of aged rats. Andrologia 42:187-192.

25. Bahk JY, JH Jung, H Han, SK Min and YS Lee. (2010). Treatment of diabetic impotence with umbilical cord blood stem cell intracavernosal transplant: preliminary report of 7 cases. Exp Clin Transplant 8:150-160.

26. Albersen M, TM Fandel, G Lin, G Wang, L Banie, CS Lin and TF Lue. (2010). Injections of adipose tissue-derived stem cells and stem cell lysate improve recovery of erectile function in a rat model of cavernous nerve injury. J Sex Med 7:3331-3340.

27. Kendirci M, L Trost, B Bakondi, MJ Whitney, WJ Hellstrom and JL Spees. (2010). Transplantation of nonhematopoietic adult bone marrow stem/progenitor cells isolated by $\mathrm{p} 75$ nerve growth factor receptor into the penis rescues erectile function in a rat model of cavernous nerve injury. J Urol 184:1560-1566.
28. Qiu X, H Lin, Y Wang, W Yu, Y Chen, R Wang and Y Dai. (2011). Intracavernous transplantation of bone marrowderived mesenchymal stem cells restores erectile function of streptozocin-induced diabetic rats. J Sex Med 8:427-436.

29. Qiu X, C Sun, W Yu, H Lin, Z Sun, Y Chen, R Wang and Y Dai. (2011). Combined strategy of mesenchymal stem cells injection with VEGF gene therapy for the treatment of diabetes associated erectile dysfunction. J Androl [Epub ahead of print]; DOI: 10.2164/jandrol.110.012666.

30. Gou X, WY He, MZ Xiao, M Qiu, M Wang, YZ Deng, CD Liu, ZB Tang, J Li and Y Chen. (2011). Transplantation of endothelial progenitor cells transfected with VEGF165 to restore erectile function in diabetic rats. Asian J Androl 13:332-338.

31. Lin G, M Albersen, AM Harraz, TM Fandel, M Garcia, MH McGrath, BR Konety, TF Lue and CS Lin. (2011). Cavernous nerve repair with allogenic adipose matrix and autologous adipose-derived stem cells. Urology 77:1509.e1-1509.e8.

32. Lin G, X Qiu, TM Fandel, L Banie, G Wang, TF Lue and CS Lin. (2011). Tracking intracavernously injected adiposederived stem cells to bone marrow. Int J Impot Res [Epub ahead of print]; DOI: 10.1038/ijir.2011.38.

33. Fandel TM, M Albersen, X Qiu, G Lin, TF Lue and CS Lin. (2011). Recruitment of intracavernously injected adiposederived stem cells to the major pelvic ganglion improves erectile function in a rat model of cavernous-nerve injury. Eur Urol [Epub ahead of print]. PubMed. DOI: 10.1016/ j.eururo.2011.07.061.

34. Weiss DJ, D Liggitt and JG Clark. (1999). Histochemical discrimination of endogenous mammalian beta-galactosidase activity from that resulting from lac- $Z$ gene expression. Histochem J 31:231-236.

35. Billinton N and AW Knight. (2001). Seeing the wood through the trees: a review of techniques for distinguishing green fluorescent protein from endogenous autofluorescence. Anal Biochem 291:175-197.

36. Castanheira P, LT Torquetti, DR Magalhas, MB Nehemy and AM Goes. (2009). DAPI diffusion after intravitreal injection of mesenchymal stem cells in the injured retina of rats. Cell Transplant 18:423-431.

37. Brulport M, W Schormann, A Bauer, M Hermes, C Elsner, FJ Hammersen, W Beerheide, D Spitkovsky, W Hartig, et al. (2007). Fate of extrahepatic human stem and precursor cells after transplantation into mouse livers. Hepatology 46:861-870.

38. Kruyt MC, J De Bruijn, M Veenhof, FC Oner, CA Van Blitterswijk, AJ Verbout and WJ Dhert. (2003). Application and limitations of chloromethyl-benzamidodialkylcarbocyanine for tracing cells used in bone tissue engineering. Tissue Eng 9:105-115.

39. Li N, H Yang, L Lu, C Duan, C Zhao and H Zhao. (2008). Comparison of the labeling efficiency of BrdU, DiI and FISH labeling techniques in bone marrow stromal cells. Brain Res 1215:11-19.

40. Onifer SM, LA White, SR Whittemore and VR Holets. (1993). In vitro labeling strategies for identifying primary neural tissue and a neuronal cell line after transplantation in the CNS. Cell Transplant 2:131-149.

41. Schormann W, FJ Hammersen, M Brulport, M Hermes, A Bauer, C Rudolph, M Schug, T Lehmann, A Nussler, et al. (2008). Tracking of human cells in mice. Histochem Cell Biol 130:329-338.

42. Salic A and TJ Mitchison. (2008). A chemical method for fast and sensitive detection of DNA synthesis in vivo. Proc Natl Acad Sci U S A 105:2415-2420. 
43. Rakic P. (2002). Neurogenesis in adult primate neocortex: an evaluation of the evidence. Nat Rev Neurosci 3:65-71.

44. Fandel TM, AJ Bella, G Lin, K Tantiwongse, CS Lin, J Pohl and TF Lue. (2008). Intracavernous growth differentiation factor-5 therapy enhances the recovery of erectile function in a rat model of cavernous nerve injury. J Sex Med 5:1866-1875.

45. Bochinski D, PS Hsieh, L Nunes, GT Lin, CS Lin, EM Spencer and TF Lue. (2004). Effect of insulin-like growth factor-1 and insulin-like growth factor binding protein-3 complex in cavernous nerve cryoablation. Int J Impot Res 16:418-423.

46. Hsieh PS, DJ Bochinski, GT Lin, L Nunes, CS Lin and TF Lue. (2003). The effect of vascular endothelial growth factor and brain-derived neurotrophic factor on cavernosal nerve regeneration in a nerve-crush rat model. BJU Int 92:470-475.
Address correspondence to: Dr. Ching-Shwun Lin

Knuppe Molecular Urology Laboratory

Department of Urology

School of Medicine

University of California

San Francisco, CA 94143-0738

E-mail: clin@urology.ucsf.edu

Received for publication June 13, 2011

Accepted after revision July 26, 2011

Prepublished on Liebert Instant Online July 27, 2011 